\title{
Effect of Switching angle on Magnetizing flux and Inrush current of a Transformer
}

\author{
Enesi Asizehi Yahaya \\ ${ }^{I}$ (Department of Electrical and Electronics Engineering. Federal University of Technology, PMB 65, Minna, \\ Nigeria
}

\begin{abstract}
Inrush current which is sometimes known as surge, or transient current is the current drawn by electrical machine or electrically operated equipment when it is first powered by an ac or dc mains which is independent on the amount of voltage supplied. This inrush current can cause sags that trip loads. When transformer is energized, the inrush current causes harmonics which can excite system resonances and cause dynamic overvoltage. The study becomes necessary because of the negative effects on transformer. This paper investigated the effect of switching angles of the flux waveform and the effect of switching angle variation on the amplitude of inrush current waveform of through Matlab simulation.
\end{abstract}

Keywords: Inrush current, Transformer, Harmonics, Switching angle, Flux waveform

\section{INTRODUCTION}

Transformer inrush current occurs when an unloaded or slightly loaded transformer is energized. The amplitude and the waveform depend on remanent flux, switching angle and switching time, the core material of the transformer (nonlinearity of the core) and the impedance of the system in which the transformer is energized [1]. Its great magnitude has a negative effect on transformer as the wave is distorted which generate higher harmonic components [2]. The inrush current is greater than the normal of the operating current of transformer and the ratio can vary from a few percent up to many times the operating current $[3,4]$ and may disconnects transformer from the supply $[5,6]$. The highest possible inrush current depends on the exact time the load is switched on. In very rare cases, it is best to apply power when the mains is at its maximum value and in some others it is better to apply power as the ac waveform passes through zero volts. The inrush current can blow up fuses and trip circuit breaker which may lead to the breakdown of that machine [7,8]. Products that use heating coils made from nichrome (nickel-chromium resistance wire) are not affected by inrush current since the variation between the cold and full temperature is generally small. Researchers have investigated and proposed different ways of limiting the inrush current in transformer such as the use of sequential phase energization technique, in which each phase of the three phase transformer is energized in sequence with time delays between them and with suitable resistor placed at the Neutral point, the use of control switch with core flux transient to reduce transient current and also the use of inrush current limiters in circuit components. The limitation becomes necessary for the protective system for the transformers. In rotating machines like three phase induction motors, the inrush current to the starting is lower due to the coils being in series across the line creating higher impedance. A star-delta starter starts the motor in star which places phase voltage across each winding on the motor which results in lower starting current and also a lower starting torque. The system of star-delta starter is being phase out with the use of electronic soft starts and by-pass contactors.

\section{Effect Of Switching Angle On Magnetizing Flux}

The nature of the transformer flux as a function of time during a transient switching on or on energization is given by equation (1):

$$
\phi(t)=\frac{V_{P}}{\varpi N}(\sin \theta \sin (\varpi t)+\cos \theta(1-\cos \varpi t)+\phi(0))
$$

Where $\mathrm{V}_{\mathrm{P}}$ is the voltage amplitude; $\mathrm{N}$ is the number of turns in the transformer coils; $\phi$ is the transformer magnetizing flux and $\theta$ is the switching angle.

The transient flux waveform on switching has constant dc offsets depending on the switching angle and the residual flux. The switching angles result in a dc offset in dc of the flux waveform in equation 1. Figure 1 shows the effects of the switching angle of the flux waveform of three angles relative to the ac supply voltage at positive zero crossing $(\theta=0)$, at voltage peak, $\left(\theta=\frac{\pi}{2}\right)$ and at negative zero $\operatorname{crossing}(\theta=\pi)$. The switching at a positive zero crossing shifts the flux waveform up to a peak flux of $1.3 \mathrm{pu}$ and vice versa for a negative zero crossing as the peak goes down to $1.3 \mathrm{pu}$. There is no dc offset when switching at a voltage peak and any other 
switching angle will result in a dc offset in between the zero crossing waveforms. The result shows that increasing the switching angle, decreases the remanent flux of the inrush current.

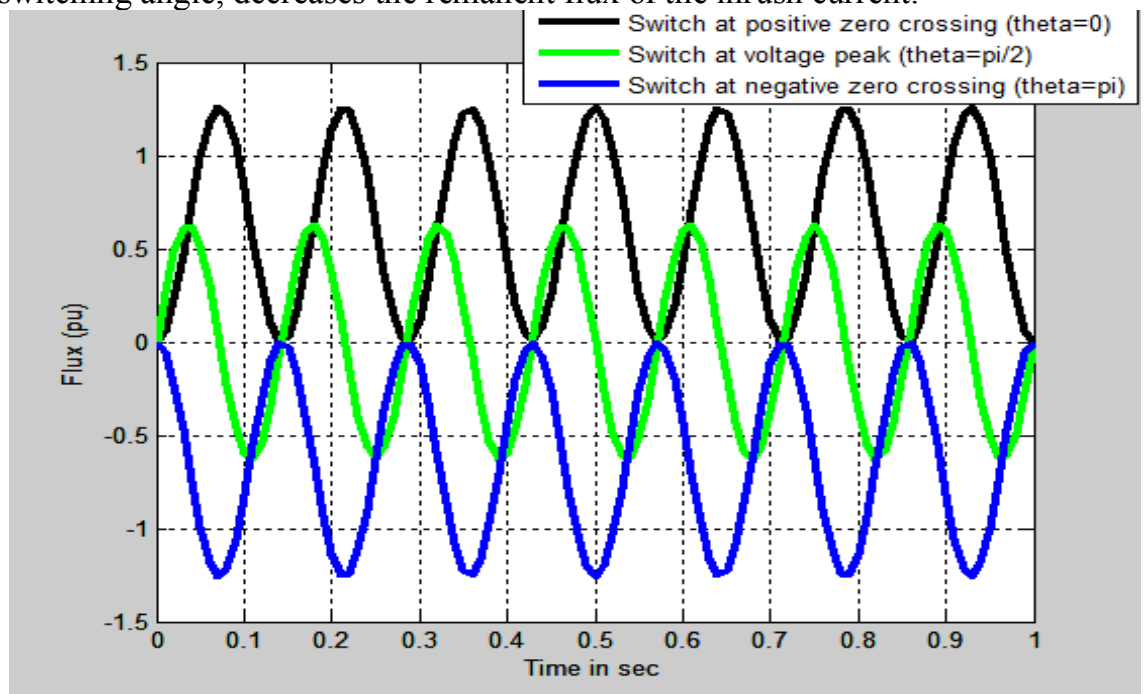

Fig. 1: Effect of switching angles of the flux waveform

III. Effect Of Switching Angle On Transient Current

The equation that gives the amplitude of inrush current as a function of time can be expressed as (2):

$I(t)=\frac{V_{m}}{\sqrt{R^{2}+\varpi^{2} L^{2}}}\left(\left(\sin (\varpi t+\theta-\phi s)-\sin (\theta-\phi s) e^{-\frac{R t}{L}}\right)\right.$

Where $\mathrm{V}_{\mathrm{m}}$ is the maximum applied voltage; $\mathrm{R}$ is the core loss resistance; $\mathrm{L}$ is the core magnetizing inductance; $\theta$ is the energization angle and $\mathrm{t}$ is the time taken in $1 \mathrm{sec}$.

The steady state power factor is:

$\cos \phi s=\frac{R}{\sqrt{R^{2}+\varpi^{2} L^{2}}}$

Figure 3 shows the graph of transient current in equation (2) for parameters $\mathrm{R} / \mathrm{L}=5$ and switching angle, $\theta=0$. This is the transient waveform for an RL switching (closing) circuit with the same time constant R/L.

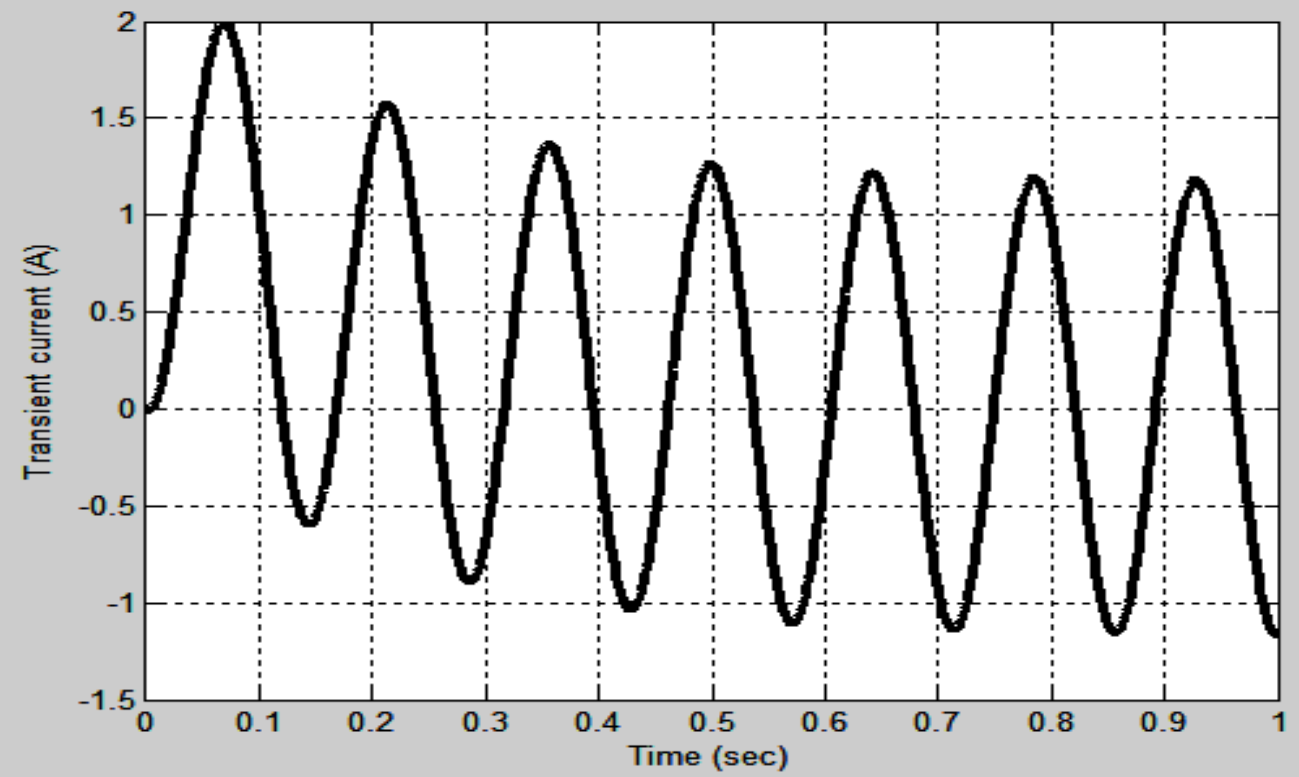

Fig. 2: Switching transient current for switching angle $(\theta=0)$ 


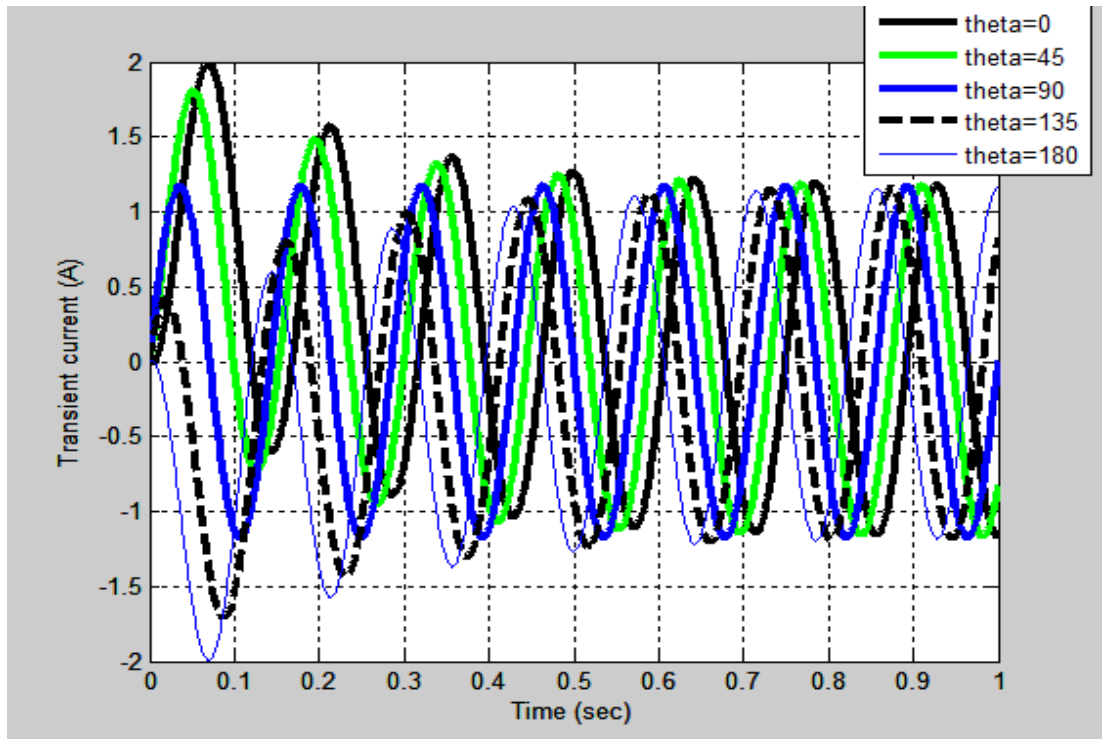

Fig. 3: Effect of switching angle variation on the amplitude of inrush current

The effect of switching angle variation on the characteristics of inrush current has been investigated in Figure 3 . The highest amplitude of inrush current in this figure is at $0^{\circ}$. Increasing the switching angle decreases the amplitude of the inrush current.

\section{Conclusion}

The effect of remanent flux and switching angle on characteristics of inrush current are investigated in MATLAB Simulink and the results show that increasing the switching angle, the amplitude of both the remanent flux and the inrush current are reduced. Therefore, the reduction of inrush current can be brought about by appropriate selection of the switching angle and the remanent flux.

\section{References}

[1] Martinez J. A, and Mork B. A. “Transformer Modeling for Low and Mid frequency Transients - a review," IEE Trans. Power Del., vol. 20, no.2 II, pp. 1625-1632. 2005

[2] Yacamini R, Abu-Nasser A (1986) The Calculation of Inrush current in Three phase Transformers. IEEE Proc. B. Electric Power Applications 133, pp. 31-40

[3] Koppiker D. A. A Modified approach of overfluxing analysis of transformers. Electrical Power and Energy Systems, vol.20, No.4 pp. 235-239. Elsevier Science Ltd. 1988.

[4] Michael Steurer and Klaus Flohlich, "The impact of inrush currents on the Mechanical Stress of High Holtage Power Transformer Coils,” IEEE Trans. On Power Delivery, vol.17, no.1, pp. 155-160, 2002.

[5] Moises Gomes-Morante and Denis W, A Wavelet based Differential Transformer Protection," IEEE Trans. On Power Delivery, vol.14, no.4, pp. 1351-1358. 1999.

[6] Smith, K.S. Ran and Leyman, B, "Analysis of Transformer Inrush transients in offshore electrical systems," IEEE Proceedings on Generation, Transmission and Distribution, vol.146, pp. 557-562, 1999

[7] Yacamini R, Abu-Nasser A (1986) The Calculation of Inrush current in Three phase Transformers. IEEE Proc. B. Electric Power Applications 133,pp. 31-40.

[8] Winders, JJ (2002). Power Transformers Principles and Applications. Marcel Dekker, Inc., Swizerland. 